\title{
The occupational roles of women with anorexia nervosa
}

\author{
Leila Maria Quiles-Cestari ${ }^{1}$ \\ Rosane Pilot Pessa Ribeiro²
}

\begin{abstract}
This study's objective was to understand how occupational roles of individuals with anorexia nervosa are configured. The sample was composed of a control group and 11 adult women with anorexia nervosa being cared for by the Eating Disorders Care Group in a hospital in Ribeirão Preto, SP, Brazil. Socio-demographic and anthropometric data were collected and the Role Checklist was applied. The results revealed a significant loss of roles for women with anorexia nervosa in relation to the performance of the roles worker, friend, and amateur/hobbyist, supporting the idea that psychosocial harm may arise from this eating disorder. The evaluation of occupational roles in the treatment of eating disorders is an important strategy for planning Occupational Therapy activities and supporting the creation of healthier spaces to enable individuals to resume occupational roles, and acquire independence and autonomy.
\end{abstract}

Descriptors: Performance Roles; Anorexia Nervosa; Eating Disorders.

\footnotetext{
${ }^{1}$ MSc, Hospital das Clínicas, Faculdade de Medicina de Ribeirão Preto, Universidade de São Paulo, Brazil.

2 Free lecturer, Associate Professor, Escola de Enfermagem de Ribeirão Preto, Universidade de São Paulo, WHO Collaborating Centre for Nursing Research Development, Brazil.
}

Corresponding Author:

Leila Maria Quiles-Cestari

Universidade de São Paulo. Faculdade de Medicina de Ribeirão Preto

Hospital das Clinicas

Av. dos Bandeirantes, 3900

Bairro: Monte Alegre

CEP: 14048-900, Ribeirão Preto, SP, Brasil

E-mail: lemariato@yahoo.com.br 


\section{Os papéis ocupacionais de mulheres com anorexia nervosa}

O objetivo desta pesquisa foi compreender como se configuram os papéis ocupacionais de pessoas com anorexia nervosa. A casuística foi composta por 11 mulheres adultas, diagnosticadas em tratamento no grupo de assistência em transtornos alimentares de um hospital de Ribeirão Preto, Brasil, e por um grupo-controle. Foram coletados dados sociodemográficos, antropométricos e aplicada a Lista de Identificação de Papéis Ocupacionais. Os resultados mostraram que houve alteração significativa nas mulheres com anorexia nervosa, com perda de papéis em relação ao padrão de desempenho do papel de trabalhador, voluntário, amigo e passatempo/amador, corroborando os prejuízos psicossociais decorrentes desse transtorno mental. A avaliação dos papéis ocupacionais no tratamento dos transtornos alimentares é estratégia importante para o planejamento de atividades de Terapia Ocupacional, fornecendo subsídios para a construção de espaços mais saudáveis, onde o fazer cria possibilidades de resgate dos papéis ocupacionais, independência e autonomia.

Descritores: Desempenho de Papéis; Anorexia Nervosa; Transtornos Alimentares.

\section{Los papeles ocupacionales de mujeres con anorexia nervosa}

El objetivo es entender como figuran los papeles ocupacionales de las personas con anorexia nervosa. La casuística fue compuesta por 11 personas diagnosticadas en tratamiento en el Grupo de Asistencia en Trastornos Alimentares de un Hospital de Ribeirão Preto-Brasil y un grupo control. Se recogieron variables sociodemográficas, antropométricas y por la "Lista de Identificación de Papeles Ocupacionales". Los resultados muestran hubo cambio, con pérdida de papeles debido a la anorexia nerviosa, con pérdida de los papeles de trabajador, voluntario, amigo y pasatiempo amador, corroborando los perjuicios psicosociales derivados de este trastorno. La evaluación de los papeles ocupacionales en el tratamiento de los trastornos alimentares es una estrategia importante para la planificación de la terapia ocupacional por la concesión de subvenciones para crear ambientes más saludables, donde las posibilidades de crear el rescate de los papeles ocupacionales, la independencia y autonomía.

Descriptores: Desempeño de Papeles; Anorexia Nervosa; Trastornos Alimentares.

\section{Introduction}

In Portuguese, the etymological origin of the word role* comes from the Greek word papyros and from the Latin word papyrus, the meaning of which is "an Egyptian sedge from which paper was produced." Gradually a social function was attributed to it, that of "a character played by an actor", "responsibility of a moral, legal, or technical nature, etc."(1).

This idea of a social role emerged in the $11^{\text {th }}$ century, mainly originating in the Social Sciences. The term is specifically a sociological or psychiatric concept. The author, a psychoanalyst and creator of the psychodrama method, was inspired by theater and became one of the pioneers in studies addressing the roles performed by individuals in society and the social concepts inherent to them(1). The author considered that the term role could be defined as "a way of functioning individuals assume at a specific time when they react to a specific situation in which other people or objects are involved"(1).

The field of Occupational Therapy, as a science and profession, developed studies concerning roles, defining them as: "a set of behaviors expected by society, molded by culture, and also molded and conceptualized by individuals"(2).

* T.N. The corresponding word in Portuguese is papel, which in English would be translated literally as 'paper'. 
One of the main theoretical references in the profession is the Model of Human Occupation (MHO) that strongly explores the concept of role and occupational role $^{(3)}$. This model seeks to recover a humanistic perspective in Occupational Therapy, associated with the General Theory of Systems, according to which the Human Being is seen as an open system, cyclical, and able to change and develop through events experienced in the environment. One view is that these systems cannot work as isolated parts; the environment and the systems result from a dynamic network of relationships ${ }^{(4)}$.

An instrument called "Role Checklist" was based on the MHO's theoretical assumptions to assess occupational roles. It was originally written by the American occupational therapist Francês Oakley in 1986. The instrument was translated and culturally adapted to Brazil, and was validated by a sample composed of individuals with chronic obstructive pulmonary disease ${ }^{(5)}$.

This inventory is intended to address information concerning ten roles individuals may have; the individuals' perceptions concerning the roles played over their lifetimes, and also the importance individuals attribute to each role(4-6).

Even though there are several Brazilian studies using the Role Checklist in different clinical situations, the configuration of occupational roles in situations of eating disorders are not sufficiently documented, particularly Anorexia Nervosa $(A N)^{(7)}$. Therefore, it is a fertile ground to explore the theme. People with AN present changed eating behavior closely linked to an excessive concern with their weight and body, in addition to an intense fear of gaining weight( ${ }^{()}$.

The etiology of these conditions is still unknown, though studies have shown that the cause may be multifactorial, including genetic, sociocultural, family and individual factors, such as some adverse experience, personality, and psychological vulnerability ${ }^{(9-10)}$.

AN has severe consequences and negatively affects individuals' organic and mental states. Hence, it is considered a disease the treatment of which is highly complex and requires the assistance of a multidisciplinary staff to provide integral care to both patients and families ${ }^{(11)}$. Hospitalization is a modality of care frequently used to reestablish the nutritional and emotional states of patients who have a more severe condition ${ }^{(9)}$. In this context, nurses are essential members of the staff who offer care to patients and families(12-13), going beyond clinical aspects, such as assessing vital signs, and administering medication and organizing a diet, among others. Psychosocial aspects of the patient's functioning are also observed in order to favor interpersonal relationships, supporting and establishing the limits necessary to promote patient autonomy, self-care, and increased wellbeing ${ }^{(14)}$.

It is believed that AN leads to psychosocial losses in daily life, as reported in cases of chronic renal failure ${ }^{(15)}$ and schizophrenia(16). Such losses include failure to play occupational roles and difficulty carrying on social relationships. Even though there are reports addressing difficulties faced in these areas ${ }^{(14,17)}$, there are no studies in the literature investigating the occupational roles of individuals with AN.

This study's objective was to understand how individuals with AN structure their occupational roles and what degree of importance they attribute to such roles, in addition to evaluating the loss of occupational roles after the disease is diagnosed.

\section{Method}

This quantitative study was conducted in the Eating Disorders Care Group (GRATA) at the Hospital das Clinicas, University of São Paulo at Ribeirão Preto, School of Medicine (HCFMRP-USP).

Two groups were selected: an Experimental Group (EG) and a Control Group (CG). The EG was composed of women with AN being cared for at GRATA- HCFMRPUSP and in follow-up in 2009. This was a convenience sample, that is, all the female patients aged from 18 to 50 years old being treated by the group were selected. Exclusion criteria were being pregnant and having a physical disability, because these conditions may independently compromise nutritional evaluation and the performance of occupational roles.

The selection of the individuals composing the CG was based on the socio-demographic characteristics found in the EG individuals to ensure comparison between the groups. Hence, we selected women aged from 18 to 40 years old, considered to be healthy according to the following inclusion criteria: a) Body Mass Index (BMI) between 19 and $25 \mathrm{~kg} / \mathrm{m}^{2}$, that is, within normal standards; b) score below 21 in the questionnaire Eating Attitudes (EAT 26), which is a screening instrument used to identify eating disorders' signs and symptoms. Scores above 21 points indicate there is a risk of developing such a disorder. Therefore, this group was matched according to gender, age, educational level, and socioeconomic conditions. The latter variable was classified according to the Brazilian Economic Classification Criteria (CCEB), $2010^{(18)}$. The snowball sampling method was used to compose this group. 
Women in the EG were invited to participate in the study and data were collected at the time they attended return outpatient visits in the HCFMRP-USP. Women in the CG were interviewed at home or workplace. The data collection process was initiated after the project was approved by the Ethics Research Committee at the Hospital das Clinicas, University of São Paulo at Ribeirão Preto, School of Medicine (protocol No. 9023/2009). The participants signed free and informed consent forms.

Socio-demographic data (occupation, educational level, time of treatment, date of birth, gender and family income) and clinical data concerning time of disease and time of treatment were collected. Additionally, an evaluation of the individuals' nutritional state was performed to verify weight and height to establish BMI. The Role Checklist was used to assess occupational roles. The same procedure concerning data collection was used for women in the CG.

Socio-demographic data were descriptively analyzed and BMI was analyzed according to the categories recommended for adults by the World Health Organization ${ }^{(19)}$. Individuals were classified in economic terms according to the Brazilian Economic Classification Criteria, 2010. Data collected using the Role Checklist were analyzed according to the protocol's specific guidelines. Data were organized according to losses, gains, changes, absences and/or continuity of roles ${ }^{(20)}$; all the possible combinations were considered regarding roles performed in the past, present and future, which translated into eight possible types of performance patterns defined as:

Loss 1: characterized by the presence of a given role in the past, combined with the absence of this same role in the present and the absence of the individual's intention or desire to perform this role in the future.

Loss 2: Characterized by the presence of a given role in the past combined with the absence of this same role in the present and the presence of the individual's intention or desire to perform this role in the future.

Gain 1: Characterized by the absence of a given role in the past combined with the presence of this same role in the present and the absence of the individual's intention or desire to perform this role in the future.

Gain 2: Characterized by the absence of a given role in the past combined with the presence of the same role in the present and the presence of the individual's intention or desire to perform this role in the future.
Continuity 1: Characterized by the presence of a given role in the past, combined with the presence of this same role in the present and the absence of the individual's intention or desire to perform this role in the future.

Continuity 2: Characterized by the presence of a given role in the past, combined with the presence of this same role in the present and the presence of the individual's intention or desire to perform this role in the future.

Change: Characterized by the absence of a given role in the past, combined with the absence of this same role in the present and the presence of the individual's intention or desire to perform this role in the future.

Absence: Characterized by the absence of a given role in the past, combined with the absence of this same role in the present and the absence of the individual's intention or desire to perform this role in the future.

Fischer's exact test was used to compare the EG and CG. The probability of type I error (alpha) was fixed at $5 \%(21)$.

\section{Results}

The EG was composed of 11 women with a median age of 29 years old $(\mathrm{Q} 1=22$ years old; $\mathrm{Q} 3=38$ years old). Six of these (54.5\%) were diagnosed with the Bulimic subtype and five participants (45.4\%) with the Restrictive subtype. In regard to education, five women (45.4\%) had completed secondary school, two (18.2\%) had a bachelor's degree, and four (36.4\%) had not completed their college education. All were active either working or studying; one of them was retired but attending college for the second time. Most of them $(n=8 ; 81.8 \%)$ were single.

Table 1 presents data concerning the EG participants' nutritional state: the median BMI was $19.4 \mathrm{Kg} / \mathrm{m}^{2}$ (Q1= $\left.16.5 \mathrm{Kg} / \mathrm{m}^{2} ; \mathrm{Q} 3=21.5 \mathrm{Kg} / \mathrm{m}^{2}\right)$. Most of the participants in this group $(63.6 \%)$ were well-nourished while four of them (36.3\%) were malnourished at different levels: two of them (18\%) were severely malnourished and two $(18 \%)$ were moderately malnourished.

The median of duration of their disease was 10 years ( $Q 1=4.5$ years; $Q 3=13.5$ years) while time of treatment was six years ( $Q 1=3$ years; $Q 3=12.5$ years), suggesting chronic and severe conditions. 
Table 1 - Anthropometric and clinical characterization of individuals in the EG $(n=11)$. Ribeirão Preto, SP, Brazil, 2010

\begin{tabular}{ccccc}
\hline Participants & $\begin{array}{c}\text { Age } \\
\text { (years) }\end{array}$ & $\begin{array}{c}\text { IMC } \\
\left(\mathbf{K g} / \mathbf{m}^{2}\right)\end{array}$ & $\begin{array}{c}\text { Time of } \\
\text { disease } \\
\text { (years) }\end{array}$ & $\begin{array}{c}\text { Time of } \\
\text { treatment } \\
\text { (years) }\end{array}$ \\
\hline 1 & 24 & 22.3 & 10 & 6 \\
2 & 39 & 20.7 & 14 & 14 \\
3 & 37 & 19.4 & 9 & 6 \\
4 & 47 & 14.6 & 13 & 13 \\
5 & 29 & 20.1 & 16 & 12 \\
6 & 21 & 16.2 & 3 & 2 \\
7 & 18 & 22.9 & 3 & 2 \\
8 & 23 & 16.8 & 10 & 4 \\
9 & 30 & 15.8 & 3 & 1 \\
10 & 21 & 19.1 & 6 & 4 \\
11 & 40 & 22.4 & 21 & 21. \\
\hline
\end{tabular}

The CG, which was composed of 11 well-nourished women, who's median age was 29 years old (Q1=22.5 years; $Q 3=37.5$ years) matched the EG. Five participants (45.4\%) had completed secondary school, two (18.2\%) had a bachelor's degree, and four (36.4\%) had attended some college. All those in the CG were either working or studying.

Figures 1 and 2 show the distribution of occupational roles over time for the $\mathrm{EG}$ and $\mathrm{CG}$, respectively.

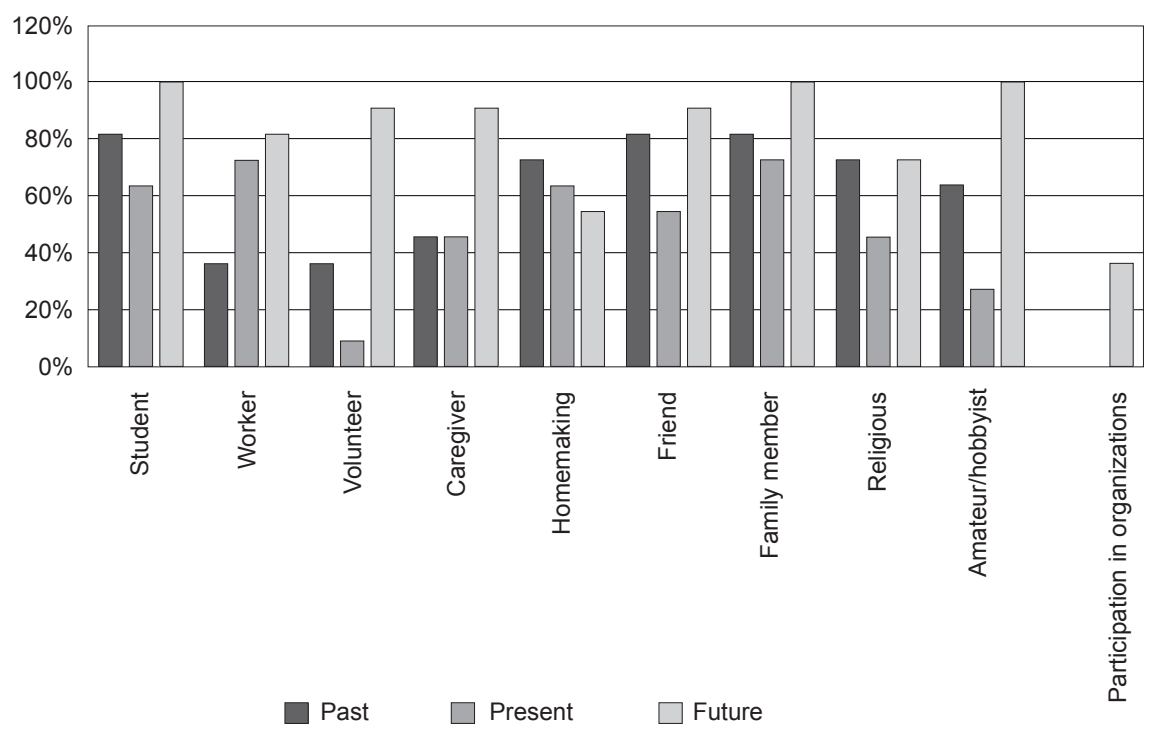

Figure 1 - Distribution of occupational roles over time for the individuals in the EG $(n=11)$. Ribeirão Preto, SP, Brazil, 2010

The women in the EG presented a reduced performance in occupational roles at the time of the study, but intended to resume such roles in the future, with the exception of homemaking. Additionally, they intended to include the role of 'participant in organizations' as a new role in their daily lives.
Women in the CG, in turn, lost few of the evaluated occupational roles. Such roles continue over time and the participants intended to continue to have them in the future. 


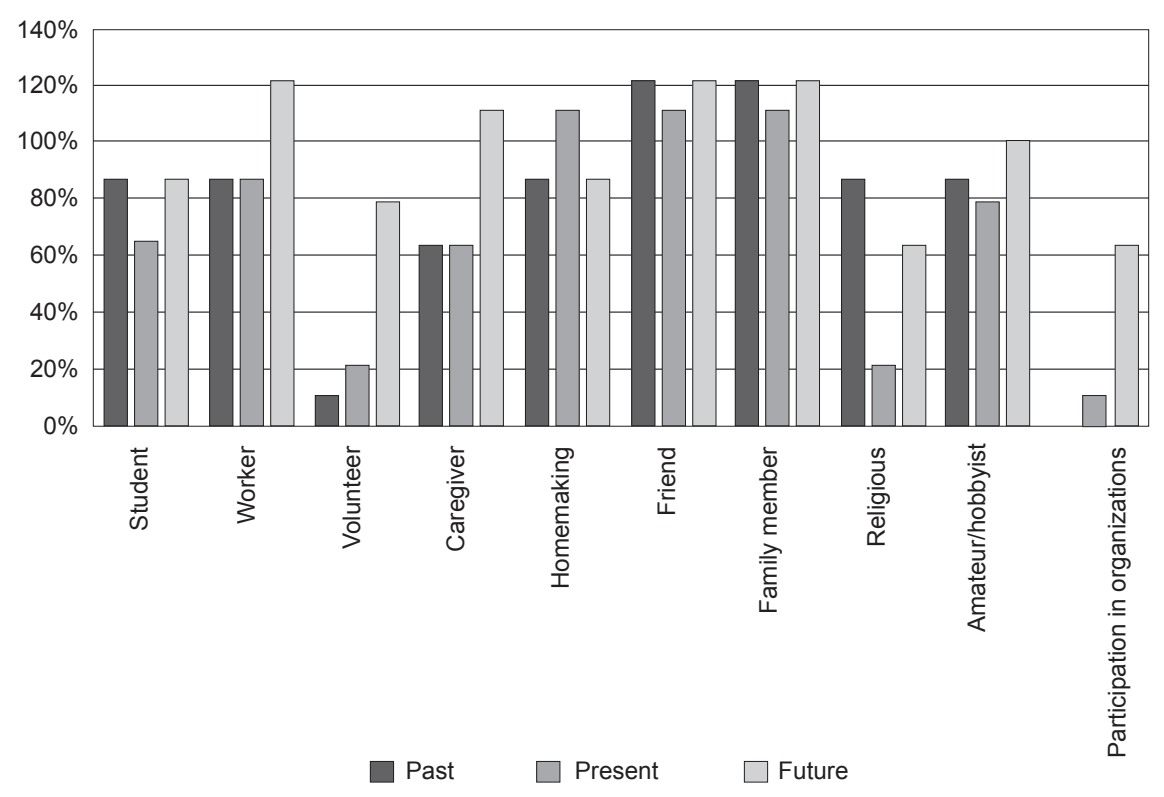

Figure 2 - Distribution of occupational roles over time of the individuals in the CG $(n=11)$. Ribeirão Preto, SP, Brazil, 2010

A statistically significant difference was found in relation to the occupational performance pattern of the roles worker, volunteer, friend and amateur/hobbyist. The performance pattern continuity 2 for the role worker showed significant differences $(p=0.043)$ : eight participants in the CG $(72.7 \%)$ had the role of worker in the past, were performing in the present, and intended to continue it in the future. Only three participants in the EG (27.2\%) gave continuity to their role as worker with the intention to continue to perform it in the future.

The role volunteer also presented a statistically significant difference, this time, in the performance pattern absent $(p=0.045)$. All the individuals in the EG intended to take this role in the future, while four individuals in the CG (36.3\%) had not played this role in the past, were not performing it in the present, and had no intention to play it in the future.

A statistically significant difference was found in the performance pattern continuity of the role friend $(p=0.032)$, that is, such a role was performed in the past, was being performed in the present, and the individual intended to perform it in the future. Even though not statistically significant, loss was observed in the performance pattern loss 2 of the EG in relation to this role, which may imply the continuity of this role in the present, as shown in Figure 1.

No statistically significant difference $(p=0.040)$ was observed in the role amateur/hobbyist between the groups in the performance pattern continuity 2 , which is related to the continuity of the role over time. The same was observed in loss $2(p=0.018)$, which means loss of the role in the present, though the individual intends to resume the role in the future.

\section{Discussion}

This study's hypothesis was that women with AN lose occupational roles with the onset of the disease. The results seem to support such a hypothesis as they show the loss of some roles in the present, among them, that of worker, friend, and amateur/hobbyist.

Even though one cannot state for sure that the loss of these occupational roles occurred due to the disease, it is possible to suggest that the condition influenced the lives of these women. Hence, among the various factors hindering the performance of these roles in the individuals' lives, AN may have interfered in the performance of the roles worker, friend, and amateur/ hobbyist.

The study's participants experienced the onset of the disease during adolescence when the main role they performed was that of student. The most important role expected when one becomes an adult is that of worker; this activity marks one's transition from adolescence to a new phase. A job is an activity that demands most of an adult's time in their daily life and enables one to achieve social and financial acknowledgement(22).

Labor has individual value and social function. Through it one attains a living, social participation and status, in addition to health when it is performed with 
pleasure $^{(23)}$. Social relationships are increased with a job and such relationships can entail both happiness and suffering(24).

At this point, one might consider the difficulties patients with AN may have relating with another person and how difficult this relationship may be to oneself and to the other people these patients live with. Occupational therapy shows that the difficulties faced by these patients in regard to their performance at work are not only caused by their times of leave and absences, but also due to difficulties they face in maintaining interpersonal relationships ${ }^{(17)}$.

Individuals with AN may show less knowledge and differentiation of themselves with another, and can also have difficulty defining their own identity and recognizing emotions. They tend to become isolated, have difficulties maintaining meaningful and significant social relationships, while potential impoverishment of interpersonal communication may occur together with a lack of empathy ${ }^{(14,25)}$. These conditions, however, cannot be generalized to all those affected with AN, though individualized care is required by those presenting these signs.

These relationship difficulties interfere in the performance of other roles, such as friend and also amateur/hobbyist since most of the time, these are performed together with other people. Difficulties in carrying on interpersonal relationships greatly harm one's participation in social activities and leisure, distancing these individuals from friends and family members ${ }^{(25)}$.

In regard to roles to be performed in the future, the EG show interest in acquiring new roles over their lifetime; they desire to double the number of roles they currently perform. Some hypotheses may be raised specifically in relation to the role volunteer. These patients may wish to help another so they can improve self-esteem, mood, motivation, and alleviate social isolation, in order to feel they have some function and are acknowledged by another. However, new studies are needed to understand these individuals' motivations to pursue this role.

It is worth noting that women from both groups (EG and $C G$ ) show loss of occupational roles over a lifetime, though without statistically significant differences. This phenomenon may be related to factors other than the disease and deserve further investigation.

\section{Final considerations}

The configuration of occupational roles identified among the studied women with AN seem to support this study's hypothesis. The performance of occupational roles that structure these women's occupational life was hindered, especially in relation to activities in social life. New studies, however, are required to identify whether this characteristic is prior to the diagnosis, that is, to verify whether these women already had difficulties relating to people or that their ability to give continuity to these roles was hampered by the onset of disease.

These results, unpublished in this field of knowledge, make an important contribution to the improvement of care provided to patients with eating disorders from the perspective of integrality of care. Therefore, health workers, especially nurses, can recognize the needs of those with $\mathrm{AN}$, valuing aspects of daily life and occupational roles involved. Additionally, these professionals can indicate Occupational Therapy as a possibility of care to support planning more specific therapeutic strategies. This modality of care is intended to help the occupational performance of people who, due to physical, mental, or social reasons, experience difficulties performing activities that sustain occupational life. Occupational Therapy is therefore, a field of knowledge that can greatly contribute to the treatment of eating disorders.

Given the psychosocial harm probably caused by the impact of AN on patients' daily life, health workers can help patients to create healthier spaces where the resumption of occupational roles is facilitated, along with independence and autonomy, and even the search for new passions in addition to that regarding the consumption of food.

We note that this study has some limitations in relation to its use of a convenience sample. Even though AN is a severe disease, its prevalence is low in relation to other psychiatric disorders. Additionally, there are no studies in the literature that permit the comparison of the results found. We suggest a larger sample be used in future studies to confirm data obtained in this study. 


\section{References}

1. Moreno JL .O psicodrama. São Paulo: Editora Cultrix; 1975.

2. American Occupational Therapy Association (AOTA). Occupational Therapy practice framework: domain and process. Am J Occup Ther. 2008;62:625-83.

3. Kielhofner G, Burke J. Modelo de ocupação humana: parte I. Rev Terap Ocup USP. 1990;1(1):55-67.

4. Kielhofner G. Modelo of human occupation: theory and aplication. 3ed. Baltimore: Williams \& Wilkins; 2002.

5. Cordeiro JR, Camelier A, Oakley F, Jardim JR. Crosscultural reproducibility of the Brazilian Portuguese version of the Role Checklist for persons with chronic obstructive pulmonary disease. Am J Occup Ther. 2007;61:33-40.

6. Oakley F, Kielhofner G, Barris R, Reichler RK. The role checklist; development and empirical assessment of reliability. Occup Ther J Res. 1986;6:157-70.

7. Cordeiro JR. Lista de Identificação de papéis ocupacionais no Brasil. [Internet] 2010.[acesso 20 ago 2010]. Disponível em: http://juniacordeiro.blog.terra. com.br/2010/03/.

8. Borges NJBG, Sicchieri JMF, Ribeiro RPP, Marchini JS, Dos Santos JE. Transtornos alimentares: quadro clínico. Medicina. (Ribeirão Preto). 2006;39(3):340-8.

9. Bighetti F, Santos MA, Ribeiro RPP, Dos Santos JE. Transtornos Alimentares: anorexia e bulimia nervosa. In: Kalinowski CE, organizadores. PROENF- Programa de atualização em enfermagem, saúde do adulto. 2 ed. Porto Alegre: Artmed; 2007. p. 9-45.

10. Galvão AN, Pinheiro AP, Somenzi I. Etiologia dos transtornos alimentares. In: Nunes MA, Apolinario JC, Galvão AL, Coutinho W. Transtornos alimentares e obesidade. 2.ed. Porto Alegre (RS): Artmed; 2006. p. 59- 71.

10.1 Cabrera C. Estratégias de intervenção interdisciplinar no cuidado com o paciente com transtorno alimentar: o tratamento farmacológico. Medicina (Ribeirão Preto).2006;39(3):375-80.

12. Grando LH, Rolim MA. TranstornosAlimentares: desafio para a enfermagem. J Bras Psiquiatr.1999;11:521-8.

13. Grando LH, Rolim MA. Família e transtornos alimentares: as representações dos profissionais de enfermagem de uma instituição universitária de atenção à saúde mental. Rev. Latino-Am. Enfermagem. 2005;13(6):989-95.

14. Santos M. Sofrimento e esperança: grupo de pacientes com anorexia e bulimia nervosa. Medicina (Ribeirão Preto). 2006;39(3):386-402.
15. Bezerra KV, Santos JLF. O cotidiano de pessoas com insuficiência renal crônica em tratamento hemodialítico. Rev. Latino-Am. Enfermagem. 2008;16(4):686-91.

16. Moll MF, Saeki, T. A vida social de pessoas com diagnóstico de esquizofrenia, usuárias de um centro de atenção psicossocial. Rev. Latino-Am. Enfermagem. 2009;17(6):995-1000.

17. Morais LV. A assistência do terapeuta ocupacional para pessoas com anorexia nervosa: relato de experiência. Medicina (Ribeirão Preto). 2006;39(3):381-5.

18. Critério Padrão de Classificação Econômica Brasil (CCEB).O Novo Critério Padrão de Classificação Econômica Brasil, 2010. [Internet] 2010. [acesso 20 jul 2010]. Disponível em: http://www.abep.org/novo/Utils/ FileGenerate ashx?id $=46$.

19. World Health Organization (WHO) Obesity: preventing and managing the global epidemic. Report of a WHO consultation. WHO Technical report Series 894 . Geneva: Word Health Organization; 2000.

20. Souza CCM. Os papéis ocupacionais da mulher fibromiálgica [monografia] Ribeirão Preto (SP): Faculdade de Medicina de Ribeirão Preto da Universidade de São Paulo; 2008.

21. Gil NAN. Os papéis ocupacionais de pacientes hospitalizados em decorrência da Aids e as contribuições da terapia ocupacional [monografia]. Ribeirão Preto (SP): Faculdade de Medicina de Ribeirão Preto da Universidade de São Paulo; 2009.

22. Kielhofner G. Modelo de ocupação humana: parte II. Rev Terap Ocup USP. 1990;1(2):114-23.

23. Porto JB, Tamayo A. Escala de valores relativos ao trabalho: EVT. Psicol Teor Pesq. 2003;19(2):145-52.

24. Guimaraes FAL, Martins MCF. Valores e prazersofrimento no trabalho: um estudo com profissionais de nível superior. Estud Psicol. 2010;27(2):133-45.

25. Cozzi F, Ostuzzi R. Relational competence and eating disorders. Eat Weight Disord. 2007;12(2):101-17. 